\title{
The progression of chronic renal failure: An unmet challenge
}

\author{
A M El Nahas and N Tamimi* \\ Sheffield Kidney Institute and the Renal Unit Kent \& Canterbury Hospital * Sheffield and Canterbury, UK
}

\section{Introduction}

An increasing number of patients require dialysis replacement therapy every year in Europe. This reflects the large number of patients with chronic renal failure (CRF) and the progressive nature of their underlying nephropathies. Worldwide, the annual incidence of acceptance rates on renal replacement programmes varies between 25 patient per million of population (pmp) in some developing countries to $58.6 \mathrm{pmp}$ in Europe, $169 \mathrm{pmp}$ in the USA [1] and 194.2 pmp in Japan [2]. In Europe, there are in excess of $312 \mathrm{pmp}$ on replacement therapy with France having one of the highest prevalence within the continent with 628 pmp [3]. Further, there are important differences in the incidence of end stage renal failure (ESRF) according to age, gender and race. In Western countries, the incidence of ESRF is lowest in children (10 pmp/year) and highest in the elderly ( $>400 \mathrm{pmp} /$ year in patients over the age of 75). The incidence of ESRF is higher in males. In the United States, the incidence of ESRF is higher in Afro-Carribeans and native Americans [4]. This reflects both an increased prevalence of CRF in these ethnic minorities as well as a higher rate of progression [4]. It also reflects the higher incidence of systemic hypertension and diabetic nephropathy in black and native Americans respectively [4]. In the United Kingdom, the incidence of ESRF is higher in Asians [5].

Correspondence and offprint requests 10: A Meguid El Nahas, Sheffield Kidney Institute, Northern General Hospital Trust, Herries Road, Sheffield SS 7 AU, UK.

\section{Pathophysiology of progressive CRF}

The progression of CRF is associated histologically with progressive glomerulosclerosis, tubulointerstitial fibrosis and vascular sclerosis. Research undertaken over the last quarter of a century has improved our understanding of the pathophysiology of these histological changes.

Glomerulosclerosis is associated with progressive renal scarring regardless of the nature of the initiating nephropathy. Numerous hypotheses have been put forward to explain the progressive nature of glomerulosclerosis. These have included the suggestion that the adaptive haemodynamic or morphological glomerular changes observed in remnant glomeruli after the loss of functional renal mass initiate glomerulosclerosis. The compensatory glomerular hyperperfusion, hyperfiltration or hypertension (a rise in intraglomerular capillary pressure) [6] or the associated glomerular hypertrophy [7] have all been implicated as maladaptive in the longterm contributing to the progression of glomerulosclerosis. The hyperperfusion / hyperfiltration hypothesis stipulated that a low protein diet would be protective against glomerulosclerosis through the correction of the adaptive haemodynamic changes [6]. Conversely, a high protein diet on the other hand has been shown to be detrimental to the progression of experimental glomerulosclerosis [8].

Others have implicated the nephrotoxicity of lipids rather than protein linking the rise of circulating lipids in CRF with their deposition within scarred glomeruli and their acceleration of the glomerular scarring process [9]. Since, a large body of evidence has confirmed that low density lipoproteins, in 
particular when oxidized, are nephrotoxic to glomerular cells [10]. A role for lipids in the pathogenesis of glomerulosclerosis has also drawn attention to the similarities between this process and that of atherosclerosis [11]. These similarities involve endothelial injury, platelet aggregation, the infiltration of the vascular/glomerular wall by monocytes/ macrophages and the proliferation of smooth muscle/ mesangial cells. Interactions between infiltrating and resident glomerular cells are mediated by the release of cytokines, chemokines and growth factors [12]. These mediators contribute to the proliferation of mesangial cells and their stimulation for the synthesis of components of extracellular matrix (ECM). These rnitogenic and fibrogenic factors include growth factors such as platelet derived growth factor (PDGF) and transforming growth factor- $\beta$ (TGF- $\beta$ ), cytokines such as interleukins 1 and 6 (IL- 1 and 6 ) and tumour necrosis factor- $\alpha$ (TNF- $\alpha$ ) and chemokines such as monocyte chemoattractant protein-1 (MCP-1) and macrophage inflammatory protein-2 (MIP-2) [13]. Of these TGF- $\beta$ is thought to be the most fibrogenic [14]. The accumulation of ECM within scarred glomeruli and their inability to break it down culminates in fibrosis and the obsolescence of the glomeruli.

The pathogenesis of tubulointerstitial fibrosis (TIF) has also received renewed interest recently. This is more relevant since the severity of tubulointerstitial fibrosis correlates better with the degree of chronic renal insufficiency when compared to glomerulosclerosis [15]. As with glomerulosclerosis, TIF has been the subject of numerous speculations and hypotheses. These included the adaptive hyperfunction of remnant proximal tubules in response to renal functional loss, the nephrotoxicity of lipids, that of iron and oxygen free radicals [16]. More recently, some have suggested that proteinuria itself was nephrotoxic [17]. This is supported by experimental observations showing that the exposure of proximal tubular cells in culture to albumin, transferrin or serum leads to their release of cytokines, growth factors and chemotactic peptides such as osteopontin [18]. Further, tubular cells respond to proteins by switching on their synthesis of ECM [18]. The release by tubular cells of chemotactic and mitogenic factors contribute to the attraction of, and infiltration of scarred kidneys by, lympho-monocytic cells. Such infiltrate is likely to play a central role in the progression of TIF. Inflammatory cells would in turn activate and stimulate the proliferation of interstitial and perivascular renal fibroblasts. The activation of these cells leads to their acquisition of myofibroblastic phenotypes and the expression of cytoskeletal proteins such as a-smooth muscle actin (a-SMA) [19]. Myofibroblasts progressively invade the scarred renal interstitium and contribute to the progression of interstitial fibrosis [19].

Vascular sclerosis often features along with glomerulosclerosis and TIF in scarred kidneys. Whislt it is likely to reflect the superimposed systemic hypertension, the severity of arteriolar hyalinosis / sclerosis is not uncommonly 'out of proportion to the sevrity of hypertension. Such vascular sclerosis may contribute to the progression of renal scarring through its ischemic effect on the remaining renal parenchyma thus exacerbating glomerulosclerosis and TIF and generating a vicious cycle culminating in end stage renal insufficiency [20]. Further, vascular injury may lead to the activation of adventitial, perivascular, myofibroblasts and their migration into the renal interstitium as described above.

\section{Management of experimental progressive renal failure}

The advances and insights made in our understanding of the mechanisms of progressive renal scarring have suggested a broad range of dietary and pharmacological approaches. In experimental animals, dietary protein restriction attenuates the development of glomerulosclerosis and slows the progression of CRF [8]. Other dietary interventions which proved to be protective have included dietary restrictions of phosphate, salt, sucrose, calories and saturated fats [8]. On the other hand, the supplementation of diet with polyunsaturated fatty acids, including fish oil (eicosapentaenoic acid) and an increase water intake are also protective against the progression of experimental renal insufficiency [8].

Numerous pharmacological interventions have also been tested with some success in experimental animals with progressive renal failure [21]. These have included the administration of antiplatelets agents and anticoagulants [21]. The reduction of renal monocylic infiltration by diets or drugs have also prevented the progression of experimental renal scarring $[8,21]$. Inhibition of cytokines, chemokines and growth factors with neutralizing antibodies or receptor antagonists have been effective in attenuating the severity of glomerulosclerosis and proteinuria and preserving renal function in rats with progressive renal diseases [11]. Finally, the reduction of systemic hypertension reduces proteinuria and preserves renal function in experimental models of renal scarring [21]. Some have suggested that all antihypertensive agents were not equally protective with angiotensin converting enzyme inhibitors being the most effective [21]. Others have shed some doubt on such assumptions and argued that the protective effect of antihypertensive agents in rats depends on the quality of systemic blood pressure control 
regardless of the nature of the antihypertensive agent used [22].

\section{Clinical interventions in CRF}

As in experimental animals a wide range of interventions have been applied to slow the progression of clinical nephropathies. These have included dietary and pharmacological interventions. Dietary interventions have included dietary protein and or phosphate restrictions as well as the supplementation of diets with fish oil. Dietary protein restrictions have been recommended to patients with progressive CRF for the last 30 years [23].

Numerous studies have suggested that such interventions slowed the progression of renal diseases. However, upon close scrutiny it became evident that many such clinical trial were flawed with inappropriate controls, small numbers of patients, limited follow-up time as well as the reliance on the use of serum creatinine measurements to estimate the rate of the progression of CRF [24]. The latter is now known to be an unreliable marker of progression when dietary protein intake is reduced leading to changes in the intake of creatine, its metabolism, generation and excretion [25]. Further, very few of the initial uncontrolled studies on dietary protein restriction payed attention to the impact of such an intervention on the nutritional status of patients with progressive renal insufficiency [24]. Over the last ten years, efforts have been made to conduct larger and better controlled prospective clinical trials on the effect of low protein diets (LPD) on the progression of CRF. Unfortunately, these have remained inconclusive. Some were inconclusive because of the poor compliance of patients to the dietary protein restriction [26]. Others had too small a number of patients making the statistical interpretation doubtful [27]. The largest study conducted so far is the Modification of Diet in Renal Disease (MRD) performed in the USA [28]. This study looked at 585 patients with a GFR between 25 and $55 \mathrm{ml} / \mathrm{min}$ and 255 patients with values between 13 and $24 \mathrm{ml} / \mathrm{min}$. Both groups were randomly allocated a target mean arterial blood pressure of 92 to $107 \mathrm{mmhg}$. The first group was randomised into a protein intake of 1.3 $\mathrm{g} / \mathrm{kg} /$ day or $0.6 \mathrm{~g} / \mathrm{kg} / \mathrm{day}$. The second group received $0.6 \mathrm{~g} / \mathrm{kg} /$ day or $0.3 \mathrm{~g} / \mathrm{kg} /$ day supplemented with a keto-amino acid mixture. Patients were followed up for up to 36 months (average 2.2 years). The projected mean declines in GFR over 3 years was not.. different between the experimental groups. Of interest, patients on a LPD had a faster decline in the renal function (reciprocal of serum creatinine) over the first 4 months of the study, thereafter they may have had a slower rate of progression. Recently, the results of the MRD were reanalysed and suggestions were made that a reduction in actual protein intake of $0.2 \mathrm{~g} / \mathrm{kg} /$ day was associated with a $29 \%$ lower rate of decline in GFR in patients with an initial value of less than $25 \mathrm{ml} / \mathrm{min}$ [29]. A metaanalysis of all major trials on LPD has also suggested a relative risk for ESRF on LPD of 0.67 (95\% Cl, 0.5 to 0.89 ) [30]. However, in this meta analysis included various trials with different levels of dietary protein reduction and consumption, different ways of measuring progression and different end points [30]. This heterogeneity makes, in my mind, such analysis pointless. Before advocating dietary protein reduction, it is important to remember that it is often associated with wasting and malnutrition. Even the MRD patients lost weight [28]. As malnutrition is a major adverse risk factor on dialysis, it is therefore unreasonalble to compromise the nutritional well being of $\mathrm{CRF}$ patients with a LPD for a doubtful, or marginal at best, effect on the rate of progression of their disease. Finally, what is the point of prescribing LPDs when it has been clearly shown that patients with ESRF reduce spontaneously their protein intake to around 0 . $6 \mathrm{~g} / \mathrm{kg} / \mathrm{day} ! ?$ ? 31$]$.

Other dietary interventions have focused on dietary restriction of phosphate. The only randomised study addressing this issue failed to show a difference in the progression rate of CRF on such a diet [32]. Studies of dietary supplementation with fish oil in CRF have shown conflicting results. The study showing a beneficial effect on the progression of mesangial IgA nephropathy in the USA was flawed by the unusually fast rate of progression of their control group [33]. The rate of progression of patients on fish oil (eicosapentaenoic acid supplementation) was in fact comparable to published reports of untreated patients with $\operatorname{Ig} A$ nephropathy in Europe.

With respect to pharmacological interventions, most have proved of little efficacy in patients with CRF. Antiplatelet agents and anticoagulants failed to affect the natural history of chronic glomerulonephritis [23]. Immunosuppression is difficult to evaluate in view of the heterogenous nature of primary and secondary glomerulonephritides. However, some trials warrant comments if only to highlight the difficulties with longterm studies of interventions in progressive CRF. In membranous nephropathy, an Italian group has repeatedly shown that a combination of chlorambucil and steroids slowed the progression of the disease [34]. When a long term study of the natural history of the disease was compared to the results of these intervention trials it appeared that the progression rate of patients with membranous nephropathy treated with chlorambucil and steroids was comparable to untreated patients [35]. Furthermore, immunosuppresion was not without its associated morbidity and mortality [34]. Studies from the NIH in the USA on the effect of immunosuppression on the progression of CRF in 
patients with lupus nephropathies have suggested that combination immunosuppression with steroids and cyclophosphamide may be advantageous [36].

Careful analysis of these studies highlights their uncontrolled nature as comparisons were made between current interventions and those practised in the sixties and seventies ! [36]. Furthermore, statistical significance was only noted when the number of patients followed-up had fallen drastically, thus casting doubt on the significance of the differences between the groups based on actuarial survival analysis [36]. In conclusion, we need, as practitioners, to be vigilant in our interpretation of published data. Sometimes, close scrutiny of the literature may avoid unproven, unnecessary and potentially harmful interventions.

It is safe to say that the only intervention of proven benefit in patients with CRF is the control of systemic blood pressure. While even this intervention has not been the subject of rigorous, prospective and randomised testing, it is safe to say that retrospective and prospective analysis have suggested a slowing down of the rate of decline in CRF of patients whose blood pressure is well controlled. Two questions follow; the first, what is the optimal level of blood pressure control we should aim for? and the second, which antihypertensive agent should we use ?

In answer to the question of level of blood pressure control, some have suggested that patients with a diastolic blood pressure inferior to $90 \mathrm{mmhg}$ had a rate of decline of GFR $50 \%$ slower than those with higher values [37]. No additional benefit seemed to be gained from a reduction of diastolic blood pressure to values lower than $85-90 \mathrm{mmhg}$ [37]. This was confirmed by a prospective, albeit small study [38]. Others have suggested that the improvement in renal function is proportional to the degree of reduction in mean arterial pressure [39]. However, in this study most patients achieved mean arterial pressure levels between 100 and $102 \mathrm{mmHg}$ and not lower. Interesting observations were recently derived from the MRD study relating to the optimal level of blood pressure control. It was suggested that patients with proteinuria benefit from a lower blood pressure when compared to the others [40]. Individuals with more than I g/day of proteinuria needed a mean arterial blood pressure around $92 \mathrm{mmhg}(125 / 75 \mathrm{mmhg})$ to acheive a similar reduction in the rate of decline in GFR to those with less proteinuria and a mean arterial pressure of $98 \mathrm{mmhg}$ (130/80 mmhg) [40]. Thus, the target of blood pressure control may need to take into consideration the severity of proteinuria with lower targets set for patients with heavy proteinuria.

The next question which arises is which drug should we use to treat hypertension in CRF. Some studies suggested that angiotensin converting enzyme (ACE) inhibitors were more protective when compared to conventional agents (diuretics, beta-blockers and calcium antagonists). Two large prospective studies one in diabetic patients [41] and the other in nondiabetic patients [42] with progressive CRF reported a beneficial effect of ACE inhibitors. Both these studies have their limitations as they both showed a better blood pressure control in patients treated with the ACE inhibitor compared to those on the other agents, thus not excluding the possibility that the additional benefit derived from a better overall blood pressure control regardless of the agent used. Furthermore, the way blood pressure was measured in these studies, casually and at long intervals, does not give the investigators an overall picture of the quality of blood pressure control. More frequent and more prolonged ( 24 hour) blood pressure monitoring is needed to ascertain whether ACE inhibitors provide additional advantages independently of blood pressure control. Meta-analysis has shown that ACE inhibitors are indeed more effective in reducing proteinuria in diabetic and nondiabetic nephropathies when compared to other antihypertensive agents [43] Other prospective studies failed to show a beneficial effect of ACE inhibitors when compared to calcium antagonists $[44,45]$. Furthermore, in patients with polycystic kidney disease [46] as well as in the elderly [47], ACE inhibitors appear to accelerate the rate of decline in renal function. These agents are not without their potential nephrotoxicity in patients with a reduction in residual renal function. It is imperative to be selective and cautious in prescribing them as they can lead to an acceleration in the decline in renal function which can, on occasions, be irreversible [48]. Finally, the therapeutic potential of ACE inhibitors may be affected by the patients' genotype as in one study patients with the ACE genotype (II) had the best response to treatment with ACE inhibitors while those with the genotype (DD) responded poorly [49].

\section{Clinical recommendations}

In patients with progressive CRF our main aim should be to avoid harm. This entails avoidance of nephrotoxic investigations (radiocontrast material) and drugs (non steroidal anti-inflammatory agents and $\mathrm{ACE}$ inhibitors). We should also be vigilant as to the causes of acute on chronic deteriorations in renal function, such as obstruction (prostatic hypertrophy amongst others) or renovascular disease in the elderly. Both should be addressed and corrected to prevent ESRF. We should follow up patients frequently and closely. We should avoid excessive protein intake but not impose dietary restrictions that could compromise their nutritional status or the quality of their lives. We should correct the metabolic consequences of CRF including hypocalcaemia, 
hyperphosphatemia and not forget the correction of metabolic acidosis as it contributes to renal osteodystrophy and malnutrition. We should detect, monitor and treat hypertension to the best of our abilities. Finally, we should attempt to initiate dialysis replacement therapy at an optimal time before the onset of significant malnutrition or cardiovascular complications as both will ultimately determine the outcome of these patients. This often means avoiding undue delay in the initiation of dialysis in the misplaced hope that some intervention is preserving renal function.

\section{References}

1. The USRDS 1995 annual data report. $V$ patient mortality and survival. Am J Kidney Dis 1995; 26 [suppl 2]: S69-S84.

2. Shinzato T, Nakai S, Akiba $C$ et al. Current status of renal replacement therapy in Japan: results of the annual survey of the Japanese Socierty for Dialysis Therapy. Nephrol Dial Transpl 1996; 11:2143-2150.

3. Valderrabano F, berthoux FC, Jones EBP, Mehls O. EDTA/ ERA Registry Report, XXV, End-stage renal disease and dialysis report. Nephrol Dial Transpl 1996; 11 [suppl 1]: 2-2].

4. Smith SR, Svetkey LP, Dennis VW. Racial differences in the incidence and progression of renal disease. Kidney Int 1991; 40: 815-822.

5. Pazianas M, Eastwood JB, MacRae KD, Phillips ME. Racial origin and primary renal diagnosis in 771 patients with endstage renal disease. Nephrol Dial Transpl 1991; 6: 931-935.

6. Hostetter TH, Olson JL, Rennke HG, Venkatachalam MA, Brenner BM. Hyperfiltration of remnant nephrons: A potentially adverse response to renal ablation. Am J Physiol 1981; 241: F85-F93.

7. Fogo A, Ichikawa 1. Evidence for a pathogenic linkage between glomerular hypertrophy and sclerosis. Am J Kidney Dis 199T; 17: 666-669.

8. Modi KS, O'Donnell MP, Keane WF. Dietary interventions for progressive renal disease in experimental animal models in Prevention of Progressive Chronic Renal Failure, El Nahas AM, Anderson S, Mallick NP (eds), Oxford Univ Press, 1993; 1: 117-172.

9. Moorhead JF, El Nahas AM, Chan MK, Varghese Z. Lipid nephrotoxicity in chronic progressive glomerular and tubulointerstitial disease. Lancet 1982; 2: 1309-1312.

10. Schlondorff D. Cellular mechanisms of lipid injury in the glomerulus. Am J Kidney Dis 1993; 22: 72-82.

11. El Nahas AM. Glomerulosclerosis: $A$ form of atherosclerosis. Nephrology (Proceedings of the Xth Int Congr Nephrol, London) 1987; 11: 1206-1220.

12. El Nahas AM. Growth factors and glomerular sclerosis Kidney Int 1992; 41 [suppl 36]: S15-S20.

13. Johnson RJ. The glomerular response to injury: progression or resolution? Kidney Int 1994; 45: 1769-1782.

14. Border WA, Noble NA. Cytokines in kidney disease: The role of transforming growth factors. Am J Kidney Dis 1993; 22: 105-113.

15. Bohle A, Mackenson-Haen S, Gise H. Significance of tubulointerstitial changes in the renal cortex for the excretory function and concentration ability of the kidney: A morphometric contribution. Am J Nephrol 1987; 7: 421-433.

16. Nath KA. The role of tubulo-interstitial processes in progressive renal disease. in Prevention of Progressive Chronic Renal Failure, El Nahas AM, Anderson S, Mallick NP (eds), Oxford Univ Press, 1993; 1: 62-97.

17. Remuzzi G, Bertani T. Is glomerulosclerosis a consequence of altered glomerular permeability to macromolecules ? Kidney Int $1990 ; 38: 384-394$.
18. Burton $\mathrm{CJ}$, Walls J. Interstitial inflammtion and scarring: Messages from the proximal tubular cells. Nephrol Dial Transpl 1996; 11: 1505-1506

19. El Nahas AM. Glomerulosclerosis: intrinsic and extrinsic pathways. Nephrol Dial Transpl 1996; 11: 773 -777.

20. Fine LG, Norman JT. Renal growth responses to acute and chronic injury: Routes to therapeutic interventions. J Am Soc Nephrol 1992: 2: S206-S211.

21. Anderson S. Pharmacological interventions for progressive renal disease. In Prevention of Progressive Renal Failure, El Nahas AM. Anderson S. Mallick NP (eds), Oxford Univ Press, 1993; 1: 173-209.

22. Griffin KA, Picken M, Bidani AK. Radiotelemetric BP monitoring. antihypertensives and glomeruloprotection in remnant kidney model Kidney Int 1994; 46: 1010-1018.

23. El Nahas AM. Wight JP. Clinical management of progressive renal failure in Prevention of Progressive Renal Failure, E Nahas AM, Anderson S. Mallick NP (eds), Oxford Univ Press. 1993. 1: 303-329.

24. El Nahas AM, Coles GA. Dietary treatment of chronic renal failure: Ten unanswered questions. Lancet 1986; 1: 597-600.

25. Levey AS. Measurement of renal function in chronic renal disease. Kidney Int 1990; 38: 167-184.

26. Locatelli F, Alberti D, Graziani G, Buccianti G et al Prospective randomized multicentre trial of effect of protein restriction on progression of chronic renal insufficiency. Lancet 1991; 337: 1299-1304.

27. Ihle BU, Becker GJ, Whitworth JA, Charlwood RA, KincaidSmith PS. The effect of protein restriction on the progression of renal insufficiency. New Engl J Med 1989; 321: 17731777.

28. Klahr S, Levey AS, Beck GJ. Caggiula AW et al. The effects of dietary protein restriction and blood pressure control on the progression of chronic renal failure. New Engl J Med 1994; 330: $877-884$

29. Levey AS, Adler S, Caggiula AW, England BK et al. Effects of dietary protein restriction on the progression of advanced renal diseases in the Modification of Diet in Renal Disease study. Am J Kidney D. 1996; 27: 652-663.

30. Pendrini MT, Levey AS, Lane J, Chalmers TC, Wang PH. The effect of dietary protein restriction on the progression of diabetic and non-diabetic renal diseases: a meta analysis. Ann Int Med 1996; 124: 627-632.

31. Ikizler TA, Greene J, Wingard RL, Parker RA, Hakim RM. Spontaneous dietary protein intake during progression of chronic renal failure. J Am Soc Nephrol 1995; 6: 1386-1391.

32. Williams PS, Stevens ME, Fass G. Irons L, Bone JM. Failure of dietary protein and phsophate restriction to retard the rate of progression of chronic renal failure: A prospeclive randornized controlled trial. Quart J Med 1991; 81: 837-855.

33. Donadio JV et al. A controlled trial of fish oil in IgA nephropathy. New Engl J Med 1994; 331: 1194-1199.

34. Ponticelli C, Zucchelli P, Passerini P, el al. A 10-year followup of a randomized study with methylprednisolone and chlora-mbucil in membranous nephropathy. Kidney Int 1995; 48: 1600-1604.

35. Schieppati A, Mosconi L, Perna A-L, et al. Prognosis of untreated patients with membranous nephropathy. New Engl J Med 1993; 329: 85-89.

36. Donadio JV, Glassock RJ. Immunosuppressive drug therapy in lupus nephritis. Am J Kidney Dis 1993; 21: 239-250.

37. Brazy PC, Stead WW, Fitzwilliam JF. Progression of renal insufficiency; role of blood pressure. Kidney Int 1989; 35: 670-674.

38. Wight JP, Brown CB; El Nahas AM. Effect of control of hypertension on progressive renal failure. Clin Nephrol 1993; 39: 305-311.

39. Alvestrand A, Guiterrez A, Bucht H, Begstrom J. Reduction of blood pressure retards the progression of chronic renal failure in man. Nephrol Dial Transpl 1988; 3: 624-631. 
40. Peterson JC, Adler S, Burkart J, Greene $T$ et al. Blood pressure control, proteinuria and the progression of renal disease. Ann Int Med 1995; 123: 754-762.

41. Lewis E, Hunsicker LG, Barin RP, Rohde RD. The effect of angiotensin converting enzyme inhibitor on diabetic nephropathy. New Engl J Med 1993; 329: 1456-1462.

42. Maschio G, Alberti D, Janin G, Locatelli F et al. Effect of angiotensin converting enzyme inhibitor benazepril on the progression of renal insufficiency. New Engl J Med 1996; 334: $939-945$.

43. Gansevoon RT, Sluiter WJ. Hemmelder MH, de Zeeuw D, de Jong PE. Antiproleinuric effect of blood pressure lowering agents: a meta-analysis of comparative trials. Nephrol Dial Transpl 1995; 10: $1963-1974$.

44. Melbourne Diabelic Nephropathy Sudy Group. Comparison between perindopril and nifedipine in hypertensive and normotensive diabetic patients with microalbuminuria. Brit Med J 1991; 302: 210-216.
45. Kanno Y, Suzuki H, Takenaka T, Saruta T. Calcium channel blockers versus ACE inhibitors as antihypertensives in polycystic kidney disease. Quart J Med 1996; 89: 65-70.

46. Chapman AB, Gabow PA, Schrier RW. Reversible renal failure associated with angiotensin-convering enzyme inhibitors in polycystic kidney disease. Ann Int Med 1991; 115: 769-773.

47. Acone D, Cante D, Cillo F, Giordano G. Giordano C. Blood pressure and progression of renal failure in the elderly. Kidney Int 1996; 49 [suppl 55]: S75-S77.

48. Devoy MAB, Tomson CRV, Edmunds ME, Feehally J, Walls J. Deterioration in renal function associated with angiotensin converting enzyme inhibitor therapy is not always reversible. J Int Med 1992; 232: 493-498.

49. Van Essen GG, Rensma PL, de Zeeuw D. Sluiter WJ, Scheffer H. Apperloo AJ. Association between angiotensin-convertingenzyme gene polymorphism and failure of renoprotective therapy. Lancet, 1996; 347: 94-95.

\begin{tabular}{|c|c|}
\hline $\begin{array}{r}\text { Transplantation } \\
\text { Society }\end{array}$ & $\begin{array}{l}\text { Co-Chairs } \\
\text { Ronald D. Guttmann, MD, FRCPC } \\
\text { Pierre Daloze, MD, FRCSC } \\
\text { Secretary-Treasurers } \\
\text { Raymond Dandavino, MD, CSPQ } \\
\text { Jean Tchervenkov, MD, FRCSC } \\
\text { For information on abstract submission and registration, contact: } \\
\text { Administrative Office } \\
\text { XVII World Congress of The Transplantation Society } \\
\text { 12,449 rue Cousineau } \\
\text { Montreal (Quebec) Canada H4K IP9 } \\
\text { Telephone: (514) 331-1998 } \\
\text { Facsimile: (514) } 334-5200 \\
\text { Deadline for abstract submission/early registration: } \\
\text { January 19, 1998 } \\
\text { Logo:- } \\
\text { in 1643, Poul de Chomedey, sieur de Moisonneure, erected o cross on Mount Royal, } \\
\text { one of two vokenic formotions on the islond of Montrel, to thank Cood for sporing } \\
\text { the Ciry from floods. }\end{array}$ \\
\hline
\end{tabular}

